\title{
Image case: Gastric tuberculosis
}

\author{
Hassan Ahmed, Nabila \\ Lecturer of Tropical Medicine, Zagazig University
}

Corresponding Author Nabila Hassan Ahmed

Mobile:

+201224892292

\section{E mail:}

nabilaahassanahmed@

gmail.com

Key words:

Tuberculosis-

Stomach

Endoscopy
35 years old male presented by recurrent hematemesis attacks and recurrent blood transfusion, no history of cough, with history of anti-tuberculosis therapy for pulmonary TB 2 years ago. General examination revealed pallor, emaciated, no lymphadenopathy, local examination showed epigastric tenderness and no organomegaly, and examination of other systems was unremarkable. Haemglobolin was $8 \mathrm{gm} \%$ (normocytic normochromic), chest X ray and abdominal ultras ound were free. Upper gastrointestinal endoscopy revealed ulcerated fundal mass. Endoscopic biopsies revealed caseating granulomas by histopathology examination.
Gastrointestinal tuberculosis is a rare disease, presented mainly in the ileoceceal region. Mycobacterium tuberculosis infection in the stomach is similar to gastric carcinoma manifestations. Gastric $\mathrm{TB}$ is mainly secondary to pulmonary TB. Antrum and prepyloric area is the most common sites affected. Gastric tuberculosis is mainly existed as ulcerative followed by hypertrophic lesions. GTB diagnosis can be established by detection of acid fast bacilli and/or caseating granuloma in gastric mucosa or submucosa. Chemotherapy is mainly give good results, while surgery may be needed in gastric outlet obstruction cases.
Ethical consideration: Consent was obtained from the case. All the information gathered from the patient was handled confidentially, and it was used only for research purpose.

Funding: None.

Conflict of interest: There is no conflict of interest.
278-279. $\underline{1237(17) 30568-3}$

Chaudhary P, Khan A, Lal R, Bhadana U. Gastric tuberculosis. Indian Journal of Tuberculosis, Volume 66, Issue 3, 2019; 411-417. https://doi.org/10.1016/j.ijtb.2018.10.004.

\section{REFERENCES}

Seth AK, Nijhawan VS, Bhandari MK, Dhaka RS, Kochar SK. Gastric Tuberculosis: A Case Report. Medical Journal, Armed Forces India. 1998; 54(3): 


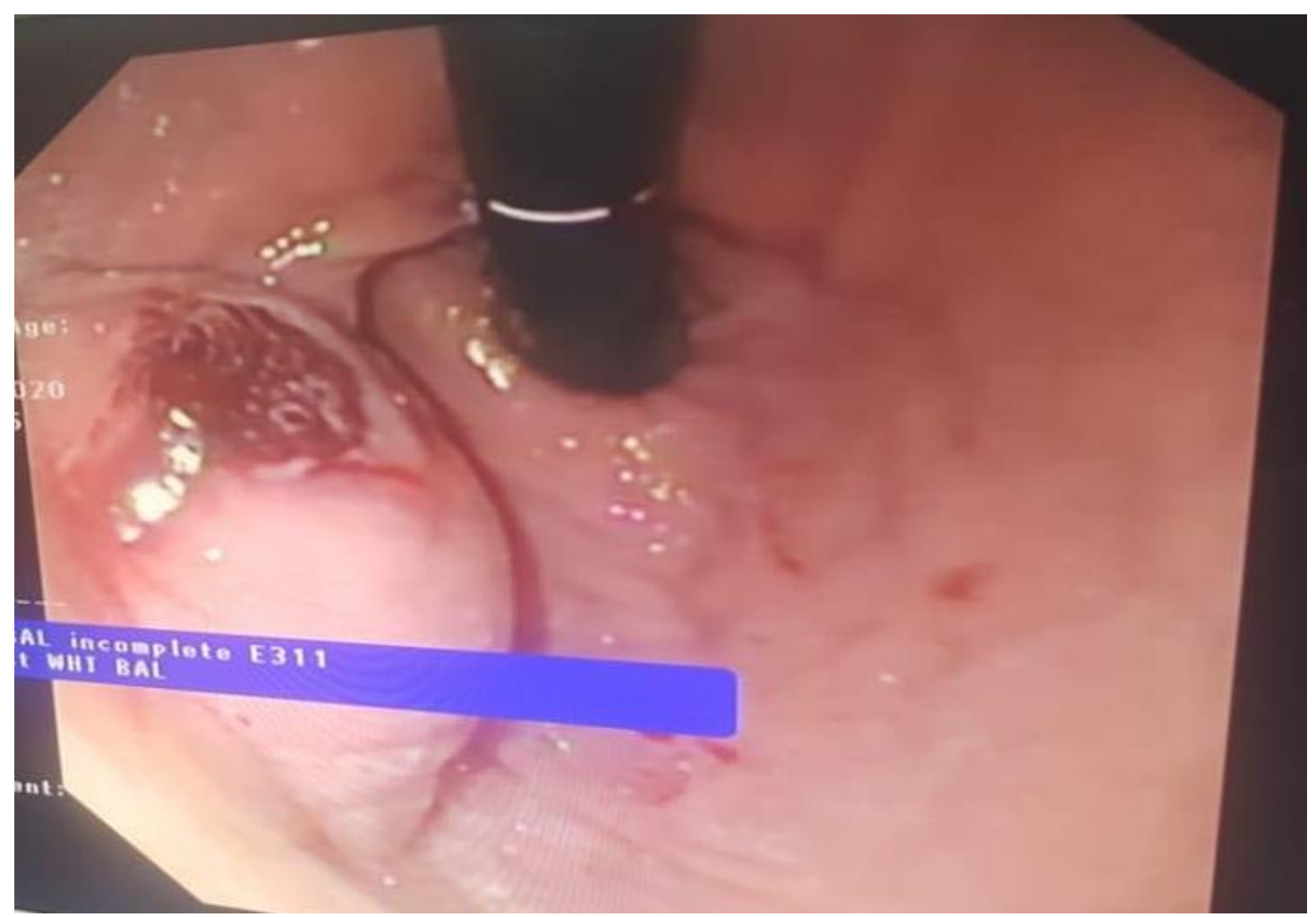

Image 1: Tuberculous ulcerating fundal mass.

Hassan AN, Afro-Egypt J Infect Endem Dis 2020; 10(4):419-420

https://aeji.journals .ekb.eg/

http://mis.zu.edu.eg/ajied/home.aspx 